\title{
Resting-State Functional Connectivity Changes in Aging apoE4 and apoE-KO Mice
}

\author{
Valerio Zerbi, ${ }^{1,2}$ Maximilian Wiesmann, ${ }^{1,3}$ Tim L. Emmerzaal, ${ }^{1}$ Diane Jansen, ${ }^{1}$ Maarten Van Beek, ${ }^{1}$ \\ ${ }^{-}$Martina P.C. Mutsaers, ${ }^{1}$ Christian F. Beckmann, ${ }^{4,5}$ Arend Heerschap, ${ }^{2}$ and Amanda J. Kiliaan ${ }^{1}$ \\ Departments of ${ }^{1}$ Anatomy, Donders Institute for Brain Cognition and Behaviour, ${ }^{2}$ Radiology, ${ }^{3}$ Geriatric Medicine, and ${ }^{4}$ Donders Centre for Cognitive \\ Neuroimaging, Radboud university medical center, 6525 EZ Nijmegen, The Netherlands, and ${ }^{5}$ MIRA Institute for Biomedical Technology and Technical \\ Medicine, University of Twente, 7500 AE Enschede, The Netherlands
}

It is well established that the cholesterol-transporter apolipoprotein $\varepsilon$ (APOE) genotype is associated with the risk of developing neurodegenerative diseases. Recently, brain functional connectivity (FC) in apoE- $\varepsilon 4$ carriers has been investigated by means of resting-state fMRI, showing a marked differentiation in several functional networks at different ages compared with carriers of other apoE isoforms. The causes of such hampered FC are not understood. We hypothesize that vascular function and synaptic repair processes, which are both impaired in carriers of $\varepsilon 4$, are the major contributors to the loss of FC during aging. To test this hypothesis, we integrated several different MRI techniques with immunohistochemistry and investigated FC changes in relation with perfusion, diffusion, and synaptic density in apoE4 and apoE-knock-out (KO) mice at 12 (adult) and 18 months of age.

Compared with wild-type mice, we detected FC deficits in both adult and old apoE4 and apoE-KO mice. In apoE4 mice, these changes occurred concomitant with increased mean diffusivity in the hippocampus, whereas perfusion deficits appear only later in life, together with reduced postsynaptic density levels. Instead, in apoE-KO mice FC deficits were mirrored by strongly reduced brain perfusion since adulthood. In conclusion, we provide new evidence for a relation between apoE and brain connectivity, possibly mediated by vascular risk factors and by the efficiency of APOE as synaptic modulator in the brain. Our results show that multimodal MR neuroimaging is an excellent tool to assess brain function and to investigate early neuropathology and aging effects in translational research.

Key words: apoE; apoE4 mice; cerebral blood flow; diffusion tensor imaging; functional connectivity; resting-state fMRI

\section{Introduction}

The only gene currently associated to sporadic Alzheimer's disease $(\mathrm{AD})$ is the $\varepsilon 4$ allele of the apolipoprotein $\mathrm{E}$ (APOE) gene (Mahley and Rall, 2000). Several mechanisms by which APOE- $\varepsilon 4$ promotes $\mathrm{AD}$ have been proposed; after brain injury, apoE is produced by astrocytes to transport cholesterol to the damaged neuronal and synaptic membranes; however, the repair and remodelling of damaged synapses appears to be less effective by apoE- $\varepsilon 4$ than other isoforms (Mahley et al., 2006; Verghese et al., 2011). Moreover, APOE- $\varepsilon 4$ carriers are more susceptible to vascular brain damages (e.g., stroke, brain hemorrhage; Zlokovic, 2011, 2013; Liu et al., 2013). This, in the end, can result in a

Received Feb. 14, 2014; revised Aug. 26, 2014; accepted Sept. 5, 2014.

Author contributions: V.Z., C.F.B., A.H., and A.J.K. designed research; V.Z., M.W., T.L.E., D.J., M.V.B., and M.P.M. performed research; V.Z., M.W., T.L.E., and M.V.B. analyzed data; V.Z. and A.J.K. wrote the paper.

This work was supported by the European Community's Seventh Framework Programme (FP7/2007-2013) under Grant agreement no. 211696 and NWO investment Grants 91106021 and BIG (VISTA). We thank Ilse Arnoldussen, Jos Dederen, Roy Haast, Karin Vos, Sabine Denissen, and Laura Mellendijk for their laboratory work; and Henk Arnts and Bianca Lemmers for their excellent care giving of our mice.

The authors declare no competing financial interests.

Correspondence should be addressed to Dr Amanda J. Kiliaan, Department of Anatomy, Donders Institute for Brain Cognition and Behaviour, Radboud university medical center, Geert Grooteplein noord 21, 6525 EZ Nijmegen, The Netherlands. E-mail: Amanda.Kiliaan@radboudumc.nl.

DOI:10.1523/JNEUROSCI.0684-14.2014

Copyright $\odot 2014$ the authors $\quad 0270-6474 / 14 / 3413963-13 \$ 15.00 / 0$ permanent loss of synaptic contacts, with gradual loss of neuronal connectivity (Bu, 2009; Verghese et al., 2011).

Investigating functional connectivity is nowadays possible by resting-state functional MRI (rsfMRI). rsfMRI examines the temporal correlations of blood oxygen level-dependent (BOLD) fluctuations between brain regions at rest, which is thought to reflect resting neuronal activity and is often referred to functional connectivity (FC; Biswal et al., 1995; Damoiseaux et al., 2006; De Luca et al., 2006). This MR technique has generated a great deal of interest among neuroscientists and has been widely used to investigate neurological disorders (Greicius, 2008).

Many studies have reported a correlation between APOE- $\varepsilon 4$, $\mathrm{AD}$, and abnormalities in functional connectivity measured with rsfMRI or task-based fMRI (Trachtenberg et al., 2012); cognitively normal young APOE- $\varepsilon 4$ carriers showed elevated restingstate activity in the default mode network (DMN) and high hippocampal activation during memory tasks; both areas that are preferentially affected in early AD (Bookheimer et al., 2000; Filippini et al., 2009). This hippocampal hyperactivation is thought to represent a compensatory response, in which increased cognitive effort is required to achieve an equal level of performance to that of non- $\varepsilon 4$ carriers (Bondi et al., 2005). Such hyperactivation is followed by a decline in FC and structural interconnectivity between cortical regions at older age (O'Brien et al., 2010; Brown et al., 2011; Machulda et al., 2011). This is in-line with studies 
showing that elderly APOE- $\varepsilon 4$ carriers have reduced FC compared with APOE- $\varepsilon 3$ carriers, even in absence of amyloid- $\beta$ plaques (Sheline et al., 2010). Alterations in the DMN have also been reported in $\varepsilon 4$-carriers (Fleisher et al., 2009), and similarly in $\mathrm{AD}$ patients (Greicius et al., 2004).

Despite an increasing amount of evidence for an association between apoE genotype and FC changes, the mechanisms underlying this relationship remain elusive (Verghese et al., 2011). Specifically, it is not clear whether changes in FC in APOE- $\varepsilon 4$ carriers have neural origins or are driven by other copathologies, such as impaired neurovascular coupling.

To determine the underlying neural or vascular origin of such changes, we investigate the relation between functional connectivity, cerebral perfusion, brain tissue microstructure, and postsynaptic density in target-replacement apoE4- and apoE-deficient mice; these mice represent mild and severe $\mathrm{AD}$ vascular risk factors, respectively, and may provide insights on the role of APOE genotype on FC changes, with or without the presence of vascular deficits.

\section{Materials and Methods}

\section{Animals}

The apoE4 founder mice were originally obtained from Taconic Transgenic Models and a colony was established at the Radboud University Medical Center (Radboud UMC). ApoE4 mice were created by targeting the murine APOE gene for replacement with the human APOE- $\varepsilon 4$ alleles cultured in E14TG2a embryonic stem (ES) cells as described previously (Sullivan et al., 1997). Resulting chimeras were backcrossed to C57BL/6J (B6) mice for eight generations. The line was derived by embryo transfer and is maintained by incrossing homozygous mice. For the present study, male and female apoE4 breeder mice were used to generate homozygous apoE4 offspring (third generation).

The apoE-deficient (B6,129P2-Apoe $\left.\mathrm{tmlUnc}^{\mathrm{Im}}\right)$ founders were originally obtained from Jackson Laboratories and a colony was established at the Radboud UMC. In ApoE-knock-out (KO) mice the APOE fragment was targeted with an apoE-specific probe (a SacI/BglII fragment) isolated from a mouse APOE cDNA clone. The strongly hybridizing phage clones obtained in this screening, a 7.8 kilobase $(\mathrm{kb})$ EcoRI fragment was isolated and compared with the restriction map. Subsequently these targeted cells were cultured in E14TG2a ES and injected into C57BL/6J (B6) mice. Resultant chimeras were backcrossed for 11 generations and intercrossed to homozygosity. The line was derived by embryo transfer and is maintained by incrossing homozygous mice (Piedrahita et al., 1992). For the present work, male and female apoE-KO breeder mice were used to generate homozygous apoE-KO offspring (third generation).

C57BL/6J wild-type mice, obtained from our colony at the Radboud UMC were used as controls. Throughout the experiment animals were housed in groups of two to seven mice per cage in a controlled environment, homogenously illuminated by normal fluorescent room light at 60 lux, with room temperature at $21^{\circ} \mathrm{C}$, and an artificial $12 \mathrm{~h}$ light/dark cycle (lights on at 7:00 A.M.). Food and water were available ad libitum.

The experiments were performed according to Dutch federal regulations for animal protection. The Veterinary Authority of the Radboud University Nijmegen Medical Centre, the Netherlands, approved all the protocols within this study.

\section{MRI}

Two cohorts of apoE4, apoE-KO, and wild-type male mice of 12 months of age (number of animals for each genotype: $n=8,10$, and 9 , respectively) and of 18 months of age ( $n=9,9$, and 10, respectively) were used for this cross-sectional study. To study genotype and aging related differences in brain function and structure, rsfMRI, cerebral blood flow $(\mathrm{CBF})$, and diffusion tensor imaging (DT-MRI) were measured in each cohort.

MRI measurements were performed on an 11.7 T BioSpec Avance III small animal MR system (Bruker BioSpin) equipped with an actively shielded gradient set of $600 \mathrm{mT} / \mathrm{m}$ and operated by Paravision
5.1 software. We used a circular polarized volume resonator for signal transmission and an actively decoupled mouse brain quadrature surface coil for signal reception (Bruker BioSpin). During the MR experiments, low-dose isoflurane was used $(3.5 \%$ for induction and $\sim 1.5 \%$ for maintenance), slightly adjusted throughout the experiment to maintain a fast and stable breathing frequency $(>130 \mathrm{bpm})$. The mice were placed in a stereotactic device with earbars and toothholder to immobilize the head. Great care was taken to fix the mouse head, as this is important to avoid movement-related artifacts, particularly when applying multishot fast acquisition MR sequences. As we did not detect movement artifacts in the EPI images, we decided not to use further methodologies to limit artifacts from movements, such as the respiratory gating, that would have increased the acquisition time. Body temperature was measured with a rectal thermometer and maintained at $37^{\circ} \mathrm{C}$ by a heated airflow device.

Gradient echo (GE) T2*-weighted images covering the entire mouse brain were acquired in three directions for anatomical reference. Subsequently, rsfMRI datasets were acquired using a single-shot spin-echo sequence combined with echo-planar imaging (SE-EPI) sequence. Although its sensitivity to image the BOLD effect is slightly reduced, SE-EPI has less susceptibility artifacts compared with GE-EPI; in addition, it is less sensitive to geometric distortion and physiological noise, which are known to generate confounding results in resting-state FC, also in rodents (Kalthoff et al., 2011). Six hundred repetitions with a repetition time (TR) of $1.8 \mathrm{~s}$ and echo time of $16.9 \mathrm{~ms}$ were recorded for a total acquisition time of $18 \mathrm{~min}$.

To study brain perfusion under resting conditions, a flow-sensitive alternating inversion recovery arterial spin labeling (FAIR ASL) technique was used (Kim, 1995; Zerbi et al., 2014). Fifteen images with increasing inversion times (TIs; 40-3000 ms) were obtained for the T1 calculations, amounting to a total scan time of $12 \mathrm{~min}$. Inversion recovery data from the imaging slice were acquired after selective inversion interleaved with nonselective inversion.

Diffusion of water was imaged as described previously (Harsan et al., 2010; Zerbi et al., 2013). In short, 22 axial slices covering the whole brain were acquired with a four-shot SE-EPI protocol. B0 shift compensation, navigator echoes, and an automatic correction algorithm to limit the occurrence of ghosts and artifacts were implemented. Encoding $b$ factors of $0 \mathrm{~s} / \mathrm{mm}^{2}$ (five $b=0$ images) and $1000 \mathrm{~s} / \mathrm{mm}^{2}$ were used and diffusion-sensitizing gradients were applied along 30 non-collinear directions in three-dimensional space. All other imaging parameters are listed in Table 1. Before each sequence, a wholebrain automatic shim protocol was applied; this includes the adjustment of field homogeneity, the adjustment of the basic resonance frequency and the adjustment of the reference pulse gain. The FWHM achieved for a square box of $6 \times 6 \times 6 \mathrm{~mm}^{3}$ was $<35 \mathrm{~Hz}$, in-line with other studies (Nasrallah et al., 2014).

\section{FC measurements}

The rsfMRI datasets were first realigned using a least-squares method and rigid-body transformation with Statistical Parametric Mapping (SPM) mouse toolbox (SPM5, University College London; http://www. fil.ion.ucl.ac.uk/spm/; Sawiak et al., 2009). Mean and maximum displacement across the six degrees of freedom (along the $x$-, $y$-, and $z$-axes and on three rotation parameters pitch, roll, and yaw) were measured in each mouse. The mean SE-EPI images of each mouse were then used to generate a study-specific template through linear affine and nonlinear diffeomorphic transformation (ANTs. v1.9; http://picsl.upenn.edu/ ANTS/). Visual inspection of the normalized dataset was performed to screen for possible normalization biases. On the template, 15 areas were selected in left and right hemisphere and back-transformed in each subject space using the inverse of the affine and diffeomorphic transformations. The selected regions were based on previous work in functional connectivity in mice (Jonckers et al., 2011), and includes: dorsal hippocampus (DH), ventral hippocampus $(\mathrm{VH})$, auditory cortex $(\mathrm{AU})$, motor cortex (M1), somatosensory cortex (S1),visual cortex (V1), and retrosplenial cortex (RS). All cortical ROI were selected $1-2$ voxels away from the edge of the cortex, to minimize the impact of susceptibility- 
Table 1. List of parameters used in each MRI scan

\begin{tabular}{|c|c|c|c|c|}
\hline & \multicolumn{4}{|l|}{ Imaging sequences } \\
\hline & Anatomical T2* W & rsfMRI & $\mathrm{CBF}$ & Diffusion tensor imaging \\
\hline Imaging method & $\mathrm{GE}$ & Spin-echo EPI & FAIR-ASL & 4-shot spin-echo EPI \\
\hline Echo time (ms) & 5 & 16.9 & 11.8 & 20 \\
\hline Repetition time & $630 \mathrm{~ms}$ & $1.8 \mathrm{~s}$ & $13.75 \mathrm{~s}$ & $7.55 \mathrm{~s}$ \\
\hline Image matrix & $512 \times 512$ & $96 \times 96$ & $128 \times 128$ & $128 \times 128$ \\
\hline Field-of-view (mm) & $40 \times 40$ & $25 \times 25$ & $30 \times 30$ & $20 \times 20$ \\
\hline Spatial resolution ( $\mu \mathrm{m} /$ pixel) & $78 \times 78 \times 340$ & $260 \times 260 \times 500$ & $234 \times 234 \times 1000$ & $156 \times 156 \times 500$ \\
\hline No. of slices & $20 \times 3$ & 9 & 1 & 22 \\
\hline Total acquisition time (min) & $\sim 8$ & $\sim 18$ & $\sim 12$ & $\sim 18$ \\
\hline
\end{tabular}

weighted artifacts, which are more prominent in areas of different tissues interface (e.g., near the skull or near the ear canals).

In-plane spatial smoothing $(0.4 \times 0.4 \mathrm{~mm})$, linear detrending, and temporal high-pass filtering (cutoff at $0.01 \mathrm{~Hz}$ ) were applied to compensate for small across-mouse misregistration and temporal lowfrequency noise. Head movement components detected from the rigid-body transformation were regressed using FSL (the FMRIB software library; Jenkinson et al., 2012). In VH, S1, and AU, voxelwise FC maps were computed using the REST MATLAB toolkit (Song et al., 2011) and group comparisons were assessed voxelwise using SPM5 with the SPMMouse toolbox. In both 12- and 18-month-old mice, two $t$ tests were performed to identify genotype differences in the framework of the general linear model. Statistical significance for voxels exceeding a minimum cluster size of 4 , to achieve cluster size $\approx 0.05 \mathrm{~mm}^{3}$ as by Dubois et al. (2008), was established at $p<0.05$, uncorrected for multiple comparisons.

FC group comparison between ROIs were calculated from the BOLD time series using total correlation and partial correlation analyses implemented in FSLNets (FSLNets v0.3; www.fmrib.ox.ac.uk/fsl). Pearson's correlation values were Fisher transformed to Z-scores for group comparisons and statistical analysis.

For an optimal characterization of the resting-state networks (RSNs), detected with our methodology in the mouse brain, a group-level estimation of functional connectivity was performed in the normalized dataset of the 12-month-old wild-type mice using an independent component analysis (ICA) method with GIFT v2.0a toolbox (group ICA of fMRI toolbox, http://icatb.sourceforge.net/; Jonckers et al., 2011; Zhou et al., 2014). The number of components for all rsfMRI data were set to be either 30, 20, or 15. Group ICA is performed using the Infomax algorithm. The group-level spatial ICA maps of independent RSNs were scaled to Z-scores with a threshold of $|Z|>1.96$, corresponding to uncorrected $p<0.025$ for two-tailed test. The ICA maps were then visually inspected and labeled based on the spatial pattern identified via an anatomical atlas (Ullmann et al., 2013).

\section{CBF calculation}

For each mouse, the FAIR images with different TIs were realigned over the first TI using a rigid-body model, implemented in SPM. Determination of $\mathrm{T} 1_{\text {selective }}$ and $\mathrm{T} 1_{\text {nonselective }}$ was performed by fitting the averaged signal intensities in each ROI with a three-parameters monoexponential T1 relaxation curve. CBF was determined in cortex, hippocampus, and thalamus using the following equation:

$$
\frac{C B F}{\lambda}=\frac{\mathrm{T}_{1 \text { non-selective }}}{\mathrm{T}_{1 \text { blood }}}\left(\frac{1}{T_{1 \text { selective }}}-\frac{1}{T_{1 \text { non-selective }}}\right),
$$

where $\lambda$ is the blood/tissue partition coefficient for water, assumed to be $0.9 \mathrm{ml} / \mathrm{g}$ (Herscovitch and Raichle, 1985; Leithner et al., 2010) and T1 blood was assumed to be $2.75 \mathrm{~s}$ at $11.7 \mathrm{~T}$ (Lin et al., 2012).

\section{Diffusion tensor MRI parameter estimation and group comparisons}

The calculation of four commonly used DT-MRI parameters, mean diffusivity (MD), fractional anisotropy (FA), radial diffusivity (RD), and parallel diffusivity $(\lambda 1)$, was performed following a protocol as described previously (Zerbi et al., 2013). Briefly, the diffusion tensor was estimated for every voxel using the PATCH algorithm (Zwiers, 2010). Thereafter, $\mathrm{FA}, \mathrm{MD}, \mathrm{RD}$, and $\lambda 1$ maps were normalized to a study-specific template through linear affine and nonlinear diffeomorphic transformation using ANTs. Regional differences between apoE4 mice and wild-type, and between apoE-KO and wild-type in spatially normalized diffusion maps were assessed voxelwise using SPM5 following the same procedure as described by Zerbi et al. (2013). Statistical significance for an individual voxel was established at $p<0.05$, with a minimum cluster size of 4 interconnected voxels (to achieve cluster size $\approx 0.05 \mathrm{~mm}^{3}$ as by (Dubois et al. (2008). As we considered the voxel based analysis (VBA) an explorative approach to investigate structural differences in the whole brain, we did not correct for multiple-comparison.

In addition, ROI of several white matter (WM) and gray matter (GM) areas were drawn on the template image based on an anatomical atlas (Paxinos and Franklin, 2004) and the resulting diffusion-related parameters were measured for further statistical analyses.

\section{Immunohistochemistry}

Directly following the MR measurements at 12 and 18 months of age, anesthetized mice were killed by transcardial perfusion with $0.1 \mathrm{M}$ PBS. The perfused brains were collected and postfixed for $15 \mathrm{~h}$ at $4^{\circ} \mathrm{C}$ in $4 \%$ paraformaldehyde fixative and thereafter stored in $0.1 \mathrm{~m}$ PBS with $0.01 \%$ sodium azide at $4^{\circ} \mathrm{C}$ for immunohistochemical staining. Eight series of 30 $\mu \mathrm{m}$ coronal sections were cut through the brain using a sliding microtome (Microm HM 440 E) equipped with an object table for freeze sectioning at $-60^{\circ} \mathrm{C}$. The tissue was stained for postsynaptic density with PSD95 antibody using one complete series of brain sections. Immunohistochemistry was performed using standard free-floating labeling procedures, as described previously (Jansen et al., 2013).

\section{PSD95}

Polyclonal rabbit anti-PSD95 (1:2000; Abcam, catalog \#ab18258, RRID: AB_444362) was used as a primary antibody. The sections were first pretreated with $0.9 \% \mathrm{H}_{2} \mathrm{O}_{2}$ in $\mathrm{PBS}$ to block endogenous peroxidise and then incubated overnight at room temperature on a shaker table. After incubation, the sections were rinsed three times with $0.1 \mathrm{M}$ PBS and incubated with the secondary antibody, donkey anti-rabbit biotin (1: 1500; Biotin-SP-AffiniPure Donkey Anti-Rabbit IgG (H+L), Jackson ImmunoResearch). After $90 \mathrm{~min}$, the sections were rinsed three times again and transferred to a solution containing Vector ABC-elite (1:800; Vector Laboratories) for $90 \mathrm{~min}$. Thereafter, visualization of postsynaptic density was achieved by incubation with DAB-Ni solution. Stained sections were mounted on gelatin-coated glass slides, dried overnight in a stove at $37^{\circ} \mathrm{C}$, dehydrated in alcohol series, cleared with xylol, and mounted in Entellan.

Quantification. The stained sections were analyzed using a Zeiss Axioskop microscope equipped with hardware and software of Microbrightfield. Brain regions were based on the mouse brain atlas of Paxinos and Franklin (2004) and quantified in five regions of the hippocampus: the inner molecular layer (IML), outer molecular layer (OML), cornus ammonis 1 (CA1), CA2, and CA3. Additionally, two regions in the cortex corresponding to the visual and somatosensory cortex were analyzed. The relevant regions were digitized at 100 times magnification with immersion oil using Stereo Investigator. The quantification of the photographs was performed using Image $(\mathrm{NIH})$. The contrast was manually 
enhanced, following the same procedure for all digitized images, and the amount of tissue stained was measured with a threshold-based approach.

\section{Statistics}

For the statistical analysis, IBM SPSS 20 software was used. Because the setup of the current study was designed to determine the effect of aging and the extent to which apoE4 and apoE-KO mice develop neuropathological traits of $\mathrm{AD}$ and not to study the effects of the apoE allele itself, statistical analyses were performed separately for the apoE4 and apoE-KO mice (apoE- $\varepsilon 4$ vs wild-type, and apoE-KO vs wild-type). Multivariate ANOVA (MANOVA) with Bonferroni corrections was conducted with between-group factors genotype and age of the animals. If the Bonferroni post hoc test indicated a significant interaction between genotype and age, the data were split for the concerning factor and thereafter analyzed again with the MANOVA. For the rsfMRI analysis, respiration of the animals was considered as covariate, to remove its confounding effect in the statistical analysis. Statistical significance was set at $p \leq 0.05$. Correlation analyses between perfusion, diffusion parameters, and PSD-95 were performed with the bivariate Spearman's correlation method in the cortex (averaged value in the S1, AU, and V1 for rsfMRI, DT-MRI, and PSD-95) and hippocampus. To avoid false-positive correlations, the statistical significance for the correlation analyses was set at $p \leq 0.01$. All values used are expressed as mean \pm SEM.

\section{Results}

The breathing of the mice was constantly monitored during the MR acquisition and used as a measure of the level of sedation of each individual mouse. During the rsfMRI and the CBF scans, the averaged respiration rate for all mice was $153 \pm 4$ and $146 \pm 5$ breaths per minutes (BPM), respectively. During the DT-MRI scan, which is the last scan of our protocol after $\sim 2 \mathrm{~h}$ anesthesia, the averaged respiration rate for all mice was $84 \pm 3$ BPM. No statistical group differences were found in respiration rate between either genotype or age, suggesting that an equal dose of anesthesia was perceived by the mice during the acquisition. Individual breathing rate changes were also uncorrelated with FC strength and CBF levels.

The displacement across the six degreesof-freedom did not show significant differences between groups, suggesting that all mice were equally influenced by motion artifacts. The higher movements were detected in the up-down direction $(0.23 \pm 0.03 \mathrm{~mm}$ averaged in all mice), whereas the displacement in other directions was lower than the voxel size. No mice were excluded after visual inspection of the normalized rsfMRI and DTI datasets.

rsfMRI: independent component analysis

Results of the ICA in 12-month-old wild-type mice are shown in Figure 1. The number of components is arbitrarily chosen based
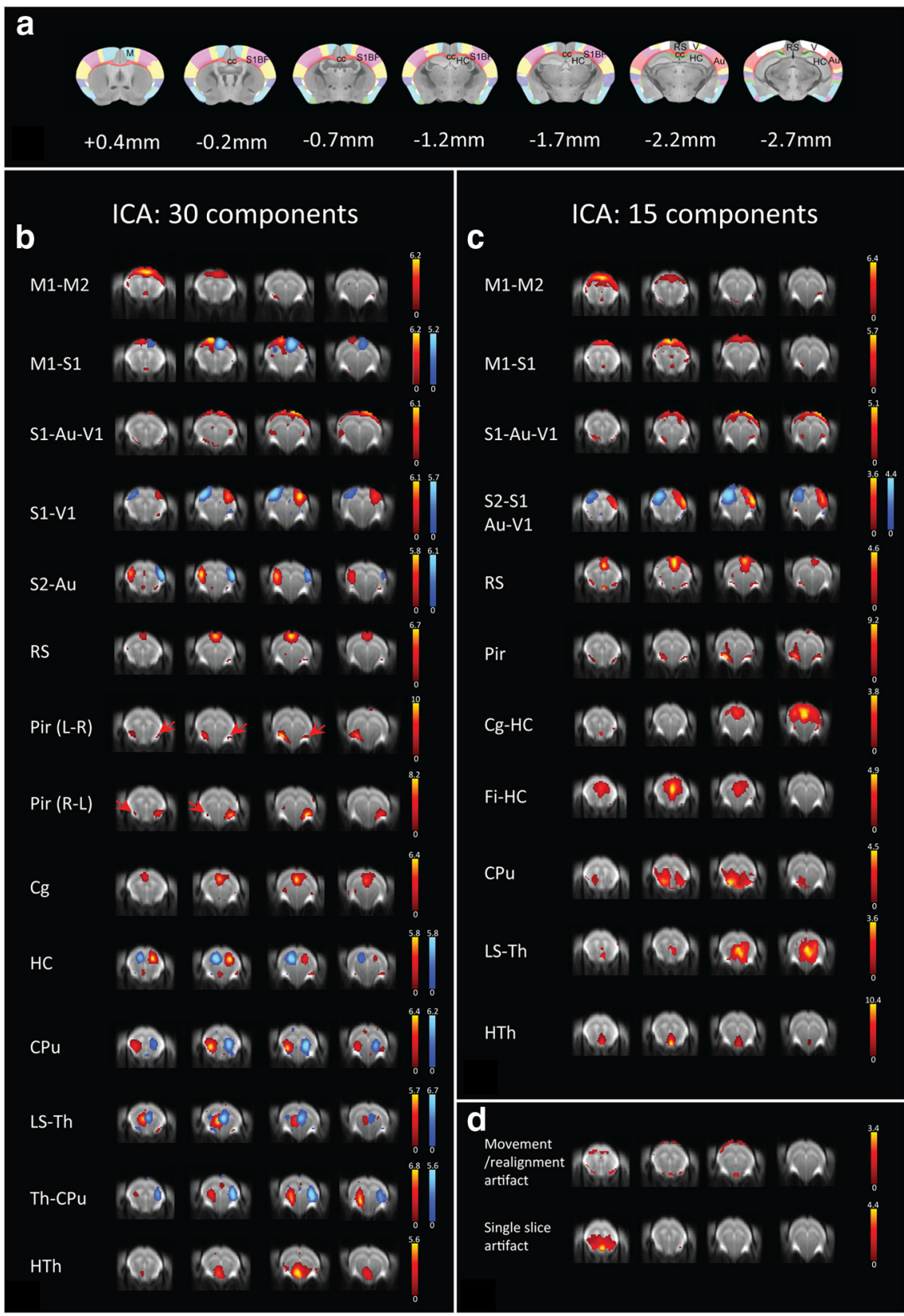

Figure 1. a, Anatomical locations of the cortical ROl, based on Ullmann et al., 2013. $\boldsymbol{b}$, FC maps defined in the 12-month-old male wild-type mice by group ICA based on 30 components. The spatial color-coded z-maps of these components are overlaid on the template SE-EPI image. Components in same anatomical locations but in contralateral regions are shown together with two different color-codes, with a higher Z-score (yellow or light blue, thresholded for $|Z|>1.96$ ) representing a higher correlation between the time course of that voxel and the mean time course for this component. Mean components comprise: $\mathrm{M1}-\mathrm{M} 2$; M1-S1; M1-S1-V1; S1-V1; S2-AU; RS; piriform cortex (Pir); Cingulum (Cg); HC; CPu; Lateral septal nuclei (LS)-Th; Th-CPu, hypothalamus (HTC).c, By reducing the number of components to 15 , many areas displayed an extended connectivity pattern across the same anatomical location, revealing a certain degree of interhemispheric connectivity. $\boldsymbol{d}, 0$ ther components having low amount of voxels at the edge of the brain, or displayed in only one slice, are considered artifacts.

on previous studies in mouse rsfMRI (Jonckers et al., 2011, 2014; Zhou et al., 2014). With 30 components, most of the components properly match specific anatomical and functional brain areas on both hemispheres (Fig. 1b); with this analysis, most of the cortical components were found to be mainly unilateral, with the exception of the motor 1 and 2 regions (M1, M2) and the motorsomatosensory-visual cortices ( $\mathrm{M} 1, \mathrm{~S} 1, \mathrm{~V} 1)$, which display a single band across the two hemispheres (Fig. 1b). By reducing the number of components to 20 and 15, more cortical regions are 


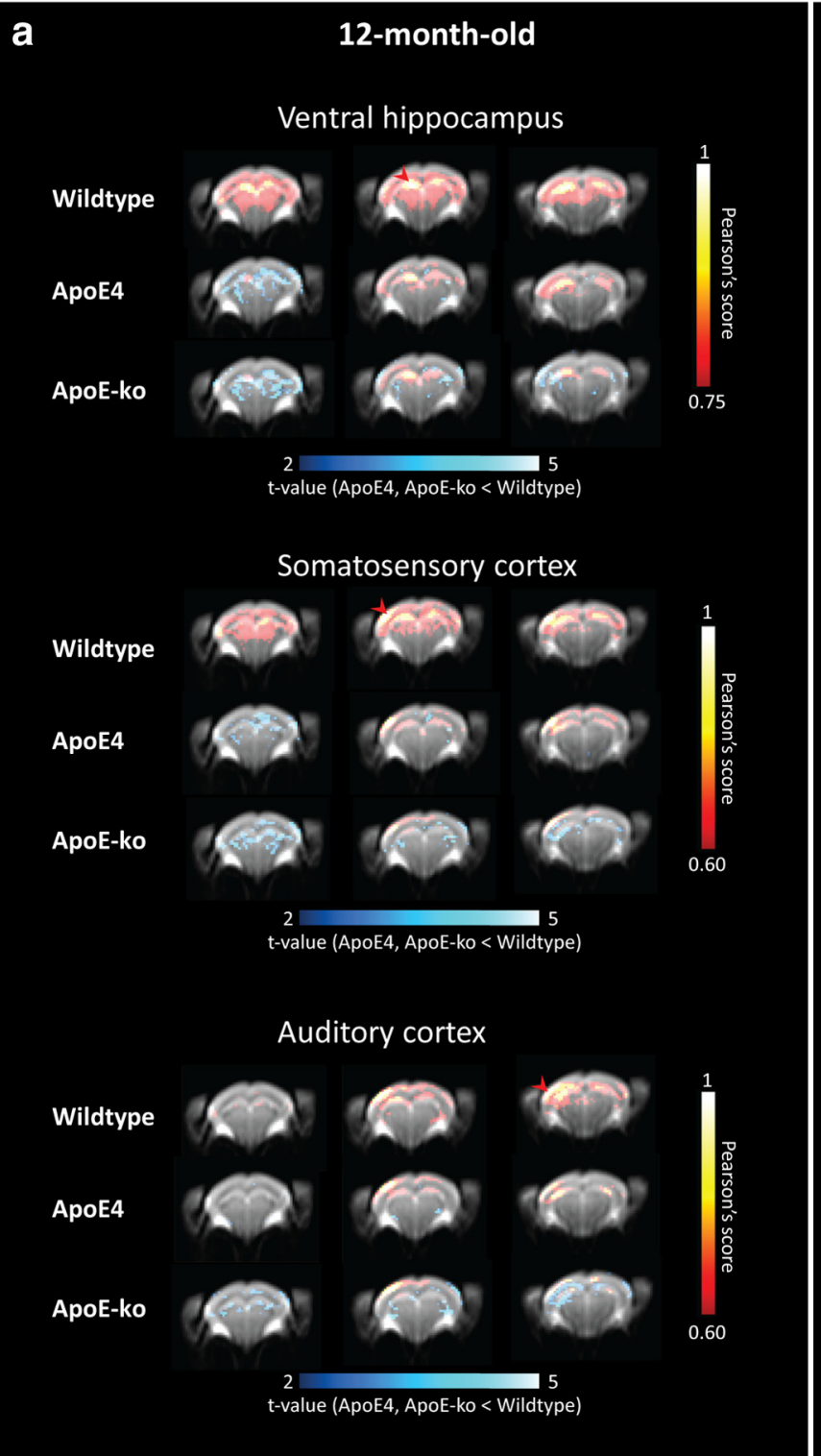

b 18-month-old

\section{Ventral hippocampus}

Wildtype
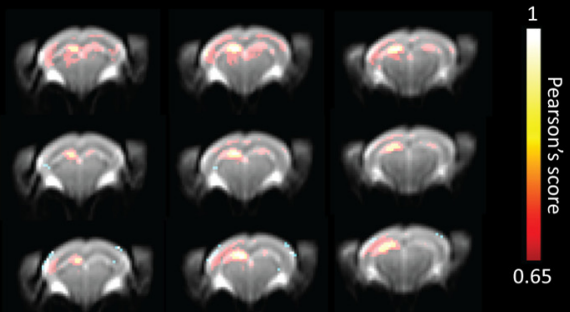

ApoE-ko

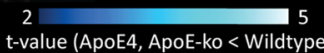

Somatosensory cortex

Wildtype
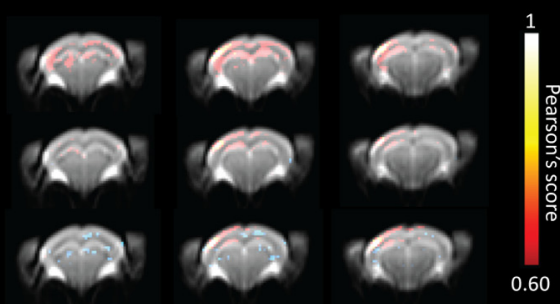

2
t-value (ApoE4, ApoE-ko $<$ Wildtype)

ApoE4

ApoE-ko

\section{Auditory cortex}

Wildtype
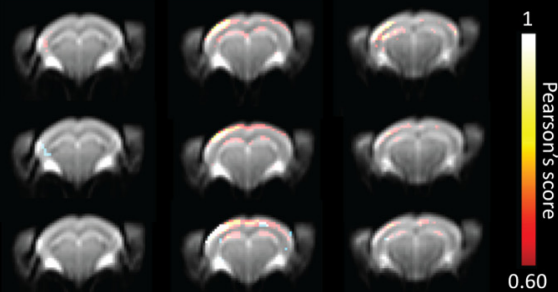

2
t-value (ApoE4, ApoE-ko $<$ Wildtype)

Figure 2. Mean FC maps defined in three ROIs in wild-type, apoE4, and apoE-KO mice. Voxel-based FC maps of the different seeds-area positioned in the VH, somatosensory cortex (SS), and AU in the left hemisphere reveal functionally connected areas. The spatial color-coded FC maps are overlaid on the SE-EPI images of the same mouse. A higher $p$ score (yellow) represents a higher correlation between the BOLD time course of the seed area and the other voxels in the brain. Voxels representing a significant reduction in $\mathrm{FC}(p<0.05$, minimum voxel cluster size $0.05 \mathrm{~mm}^{3}$ ) between apoE4, apoE-KO compared with wild-type are shown in blue. No voxels indicated an increased FC in these genotypes at both ages. $\boldsymbol{a}$, At $12 \mathrm{months}$ of age, a strong interhemispheric connectivity between right and left hippocampus is notable. In the cortical regions, the connectivity is covering SS, AU, and motor cortices, mainly unilaterally distributed but with extent also in contralateral areas, in the hippocampus and in few thalamic nuclei. VBA defined the location of significant $\mathrm{FC}$ reduction in the selected ROI in apoE4 and apoE-KO mice. $\boldsymbol{b}$, At 18 months of age, the strength of correlation and the interhemispheric connectivity were visibly reduced but still present due to aging. Differences between genotypes were less visible and present mainly in the apoE-KO mice.

covered by one band bilaterally; other brain regions that displayed a highly unilateral pattern in the 30-component analysis, such as the $\mathrm{HC}$, the caudate-putamen $(\mathrm{CPu})$, and the thalamic nuclei (Th), showed more prominent bilateral activity (Fig. 1c).

Mean FC patterns in the different mice groups from seeds in $\mathrm{VH}, \mathrm{S} 1$, and AU are shown in Figure 2. Overall, a strong bilateral connectivity is notable when seeding in hippocampal regions. In the cortex, we detected a strong connectivity covering somatosensory, auditory, and motor cortices, with some extent also in their corresponding contralateral regions.

The VBA of these patterns revealed a widespread $\mathrm{FC}$ reduction in both apoE4 and apoE-KO mice compared with wild-type, par- ticularly visible at younger age. No voxels indicated an increase FC in these genotypes.

Total correlation analyses

To compare the FC patterns in different genotype and ages, rsfMRI data were statistically analyzed based on total correlation (Fig. 3) and partial correlation (Fig. 4).

The multivariate ANOVA showed overall significant aging and genotype effects when comparing apoE4 and apoE-KO with wild-type mice (Fig. 3b,c). In both apoE4, apoE-KO, and wildtype mice, 18-month-old animals showed decreased FC levels compared with 12-month-old mice. Most striking aging differ- 
a

\section{Wild type}

\section{ApoE4}

\section{2-month-old}
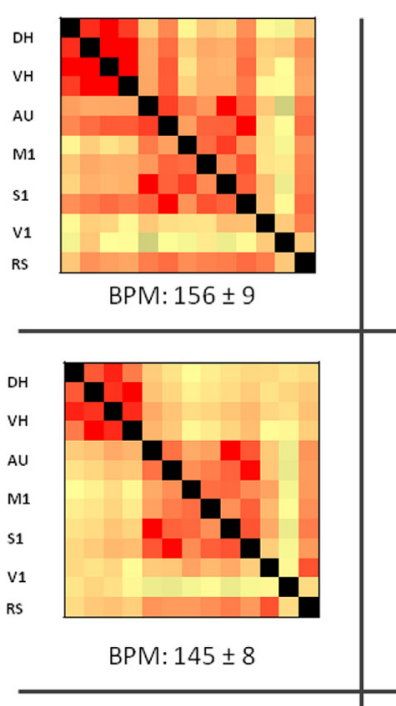

VH

AU

M1

S1

V1

RS

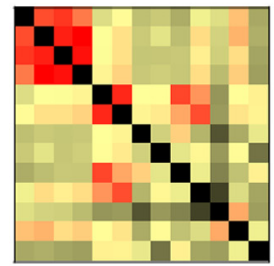

BPM: $144 \pm 5$ 18-month-old
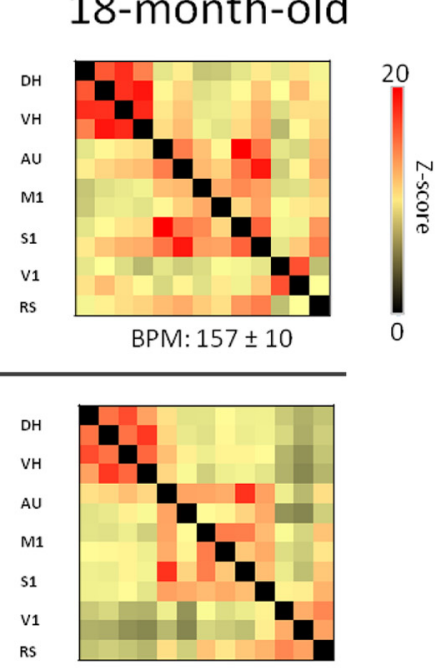

BPM: $167 \pm 5$

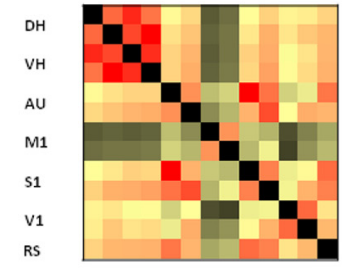

BPM: $142 \pm 9$ b

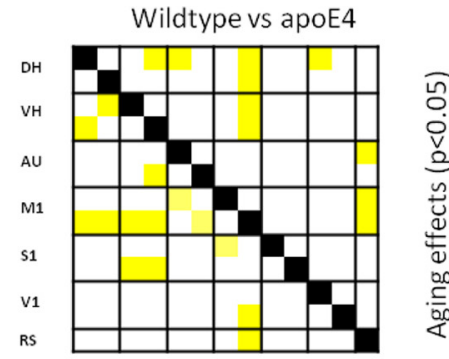

Genotype effects $(p<0.05)$

C

Wildtype vs apoE-ko

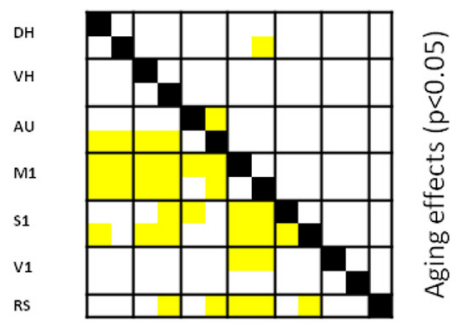

Genotype effects $(p<0.05)$

Figure 3. Resting-state FC based on total correlation analyses of $15 \mathrm{ROI}$ in the mouse brain. $\boldsymbol{a}$, Total correlation matrices of wild-type, apoE4 and apoE-KO mice at 12 - and 18 months of age. Some characteristics of the mouse brain connectivity are consistent within different mouse models and age-effect; for example, it is visible a strong bilateral connectivity between DH and VH. AU, M1, S1, and RS also show a high degree of interconnectivity, as well as high FC between V1 (BPM; average \pm SE). $\boldsymbol{b}$, Statistical analyses of FC is shown as a matrix, to reveal significant differences between genotypes (bottom-right) and between aging (top-right) for each ROI-ROI connection. Because no genotype $\times$ age interactions were seen, data were analyzed as genotype effects, independent of age, and aging effects, independent of genotype. ApoE4 mice displayed a reduction of $\mathrm{FC}$ at both ages, compared with wild-type, between several regions; particularly, a reduced $\mathrm{FC}$ is seen between dorsal and ventral hippocampus and M1, AU, and SS. Intracortical FC reduction are also seen, affecting primarily the AU-M1-SS system. Aging effects are also shown, revealing a reduction of FC over time between 12- and 18-month-old mice. Most striking differences are found between $\mathrm{M} 1$ and DH, VH and RS. c, Statistical analyses revealed strong reduction of $\mathrm{FC}$ in apoE-K0 mice compared with wild-type mice, at both ages. These deficits seem to occur primarily in the hippocampal-cortical connectivity, but also between M1, AU, S1, and RS. Reduced FC due to aging is seen between $\mathrm{M} 1$ and $\mathrm{DH}$, and between $\mathrm{AU}$ cortices.

ences were located in the connectivity between motor cortices (left and right) and hippocampus, and, specifically for apoE4 and wild-type mice, between motor cortex and retrosplenial cortex (Fig. 3b,c, top-right). Reduced FC between auditory cortices was also detected in apoE-KO and wild-type animals.

The pairwise comparison also revealed significant lower FC in apoE4 and apoE-KO mice, independent of age. These reductions in FC commonly affected auditory, motor, and somatosensory cortices and hippocampal areas (Fig. 3b,c, bottom-left). However, stronger reductions of FC were seen in the apoE-KO mice compared with wild-type, also including the motor-visual connectivity and retrosplenial cortex.

In both group comparisons, the MANOVA revealed no significant genotype $\times$ age interactions.

\section{Partial correlation analyses}

The multivariate ANOVA of the partial correlation values (with $Z$-value thresholded at $|z|>1.96$ ), showed overall significant genotype effects (Fig. 4); the apoE4 had lower FC compared with wild-type in the direct connectivity between auditory cortices although not significant, $p=0.052$. In the apoE-KO mice, a more severe reduction was found between somatosensory and motor cortices (Fig. 4b). Reduced partial correlation was found in the motor-somatosensory cortices connectivity for apoE-KO and wild-type mice due to aging ( $p=0.034$, data not shown). Also in the partial correlation analyses, the MANOVA, revealed no significant genotype $\times$ age interactions.

\section{CBF}

To study differences in cerebrovascular health between the mice groups, we measured CBF with a FAIR ASL. Three ROIs on the left and right brain hemispheres were analyzed: cortex, hippocampus, and thalamus. Because no intraindividual differences in CBF between right and left hemispheres were detected between mice groups (data not shown), values from both sides were averaged.

In the comparison of apoE4 with wild-type, the MANOVA revealed a genotype $X$ age interaction in the cortex and in thalamus ( $p=0.027$ and $p=0.026$, respectively); after splitting the data for age and for genotype, we found that 18-month-old apoE4 mice have significantly lower CBF in these ROIs compared with wild-type at the same age $(p=0.005$ for the cortex and $p=$ 0.002 for the thalamus), and also compared with 12-month-old apoE4 animals ( $p=0.005$ and $p=0.002$, respectively; Fig. 5). Contrarily to what is seen in the FC results, in the 12-month-old mice we did not detect any difference between wild-type and apoE4. 

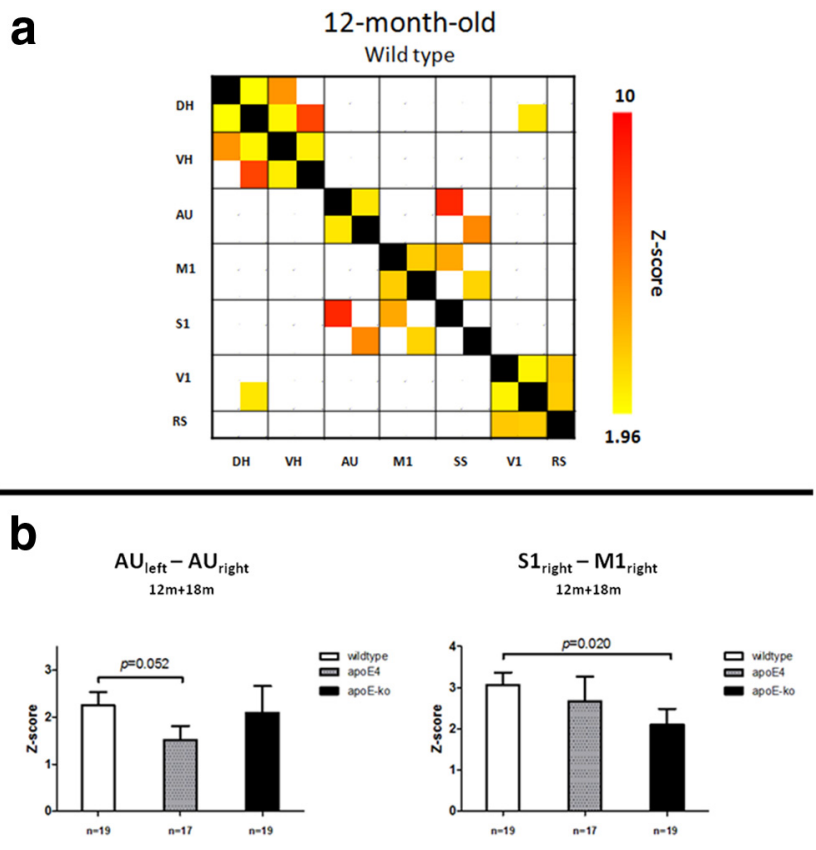

Figure 4. Resting-state FC based on partial correlation analyses of 17 ROls in the mouse brain. $\boldsymbol{a}$, Averaged partial correlation matrix of 12-month-old wild-type mice. Compared with total correlation analysis, the partial correlation highlights the direct connectivity between two regions, by regressing the temporal BOLD signal from all other ROI. These matrices were highly similar between different genotypes and ages (data not shown) and revealed unique features of mouse brain connectivity; in particular, a significant direct interhemispheric connectivity is seen within the $\mathrm{DH}, \mathrm{VH}, \mathrm{AU}, \mathrm{M1}$, and V1. Among the cortical regions, we could not detect a significant direct interhemispheric connectivity only in the $\mathrm{S1}$ region. However, a strong intrahemispheric connectivity is seen between S1, M1, and AU and between V1 and RS. Resulting connectivity were thresholded at $|Z|>1.96$, corresponding to uncorrected $p<0.025$ for two-tailed test, based on the 12-month-old wild-type data. $\boldsymbol{b}$, From the selected areas, reduced interhemispheric direct connectivity between auditory cortices was detected in apoE4 mice; significant reduced $\mathrm{FC}$ in the apoE-KO mice, independent of age, was seen between the $\mathrm{S} 1$ and the M1. Data represent mean $\pm \mathrm{SE}$.

Compared with wild-type, the apoE-KO mice showed a significant lower CBF in the cortex $(p=0.022)$, independent of age. In the hippocampus and in the thalamus a slight reduction of CBF was also seen, although it did not reach statistical significance ( $p=0.117$ and $p=0.084$, respectively). No aging effects were seen in both genotypes.

\section{DT-MRI}

In DT-MRI the water diffusivity, assessed in multiple directions, is used to reconstruct an ellipsoid for every voxel to model the diffusion. The MD describes the size of the ellipsoid, while its shape is quantified by the FA. RD and $\lambda 1$ further describe the shape of the ellipsoid and its directionality with respect to the main fiber orientation. Differences of diffusion tensor derived indices were determined separately in each age group with an explorative VBA and, with a ROI-based approach. The VBA can detect the occurrence of diffusion changes at higher spatial resolution and is the option of choice when there is no prior knowledge about the expected changes; however, these changes must then be confirmed by a proper statistical analysis in a ROI-based approach. For the VBA, $t$ value maps (for a $p<0.05$, and minimum voxel cluster size set at $0.05 \mathrm{~mm}^{3}$ ) were overlaid with FA and MD template images (Figs. $6 a, b, 7 a, b$ ).

Several differences in diffusion parameters were detected from the VBA. Among them, the most striking seem to be an increased MD in the cortex and hippocampus, commonly found in 18-month-old apoE4 and apoE-KO mice compared with wildtype (Fig. $6 a, b)$. In the apoE4 mice, a reduction of FA is also noticeable in the molecular layer of the hippocampus, and in other cortical regions such as in the retrosplenial and in the piriform cortices. In the apoE-KO mice, an increased FA in the external capsule is seen in 12-month-old mice. In both apoE4 and apoE-KO mice, differences in FA and MD were seen near to the ventricle area, possibly due to partial volume effects.

With the ROI-based approach, we measured a higher MD in the $\mathrm{DH}$ in apoE4 mice $(p=0.038)$, reflected by increases (not significant $)$ in both $\mathrm{RD}(p=0.056)$ and $\lambda 1(p=0.231)$. An increased MD in the apoE4 mice was also found in the corpus callosum (CC) at -1.7 from bregma $(p=0.016)$, driven by a higher $\lambda 1(p=0.001)$; similar differences were seen also in the external capsule (EC; higher MD: $p=0.035$; higher $\lambda 1: p=$ $0.015)$; however, no FA changes were measured in these WM regions. The FA differences found by VBA, but not confirmed by the ROI-based approach could therefore be: (1) indicative for a minor change in diffusion proprieties, and (2) true only for a limited part of the structure of interest.

Few other differences were found, such as an increase MD in the $\mathrm{DH}$ in apoE-KO mice and an increased MD in the MEctx in apoE4 mice, although were not significant $(p=0.08)$. No significant aging effect or genotype $\times$ age interactions were seen in the MANOVA.

\section{PSD-95}

Levels of postsynaptic density were visualized and quantified with polyclonal rabbit anti-PSD95 and are shown as relative values compared with wild-type mice (Fig. 8). In the 12-month-old animal group, we found a significant reduction of PDS-95 staining in apoE-KO mice compared with wild-type in the IML $(p=$ $0.005)$ and in the CA3 ( $p=0.046$; Fig. $8 c)$. In 18-month-old animals, reduced PSD-95 levels in both apoE-KO and apoE4 mice compared with wild-type was seen in the IML and OML; however, these differences were only significant in the apoE4 group ( $p=0.043$ and $p=0.039$, respectively; Fig. $8 d$ ). Because the staining of the two groups was not performed at the same time, we could not assess aging effects on the different genotypes.

The two-tailed Spearman's correlation test revealed a strong positive correlation between PSD-95 levels and CBF in both the hippocampal region $(p=0.003)$ and in the cortex $(p=0.006)$. When we split the data for genotype and age, we detected a similar positive correlation for all groups, but smaller in magnitude. The correlation in the cortex was nearly significant at both 12 and 18 months of age $(p=0.072$ and $p=0.043)$, and more pronounced in the apoE4 mice $(p=0.014)$ than in apoE-KO $(p=0.087)$ and wild-type $(p=0.033)$.

No correlations were found between PSD-95 and DT-MRI parameters, neither a significant correlation between DT-MRI and CBF for the same regions.

\section{Discussion}

Target-replacement apoE4 and apoE-KO mice are attractive models to investigate the role of apoE and vascular risk factors in relationship with $\mathrm{AD}$-like pathology, such as changes in brain FC. However, the technical challenges to obtain good-quality MR images and the lack of knowledge of murine brain network systems have been strong limiting factors for these studies. Recently, new dedicated hardware and methods for acquisition and data analysis enabled the analysis of rsfMRI in mice, resulting in a growing number of publications (Jonckers et al., 2011, 2014; Guilfoyle et al., 2013; Nasrallah et al., 2014). 

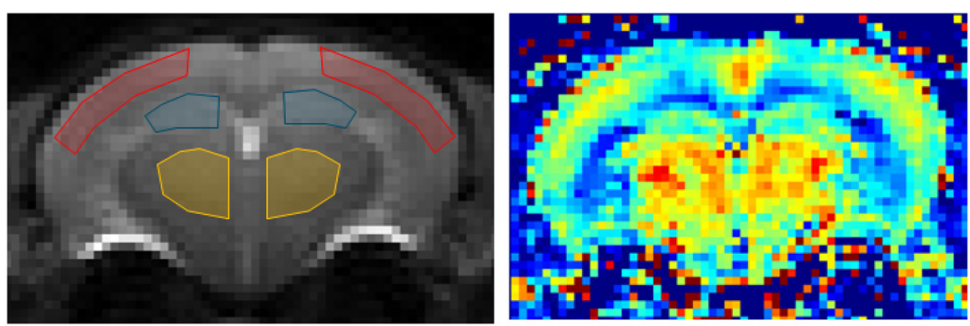

b

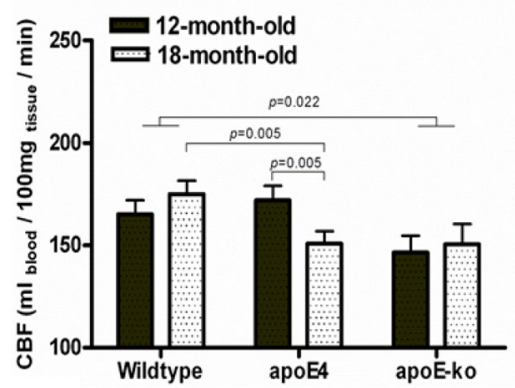

Hippocampus

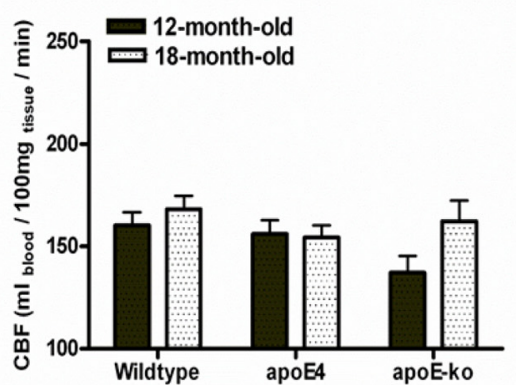

Thalamus

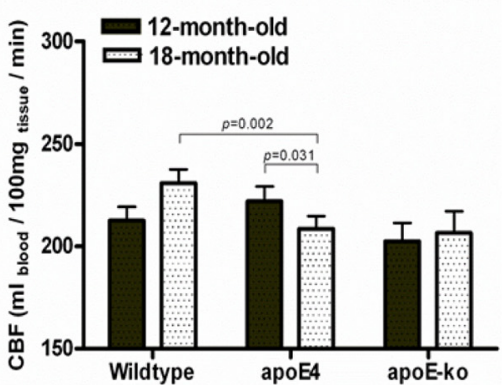

Figure 5. a, CBF was measured in apoE4, apoE-KO, and wild-type mice at 12 and 18 months of age in three different ROls: cortex (including somatosensory, auditory, and visual cortices), hippocampus, and thalamus. The area corresponding to the retrosplenial cortex was excluded, because it overlaps with the azygos pericallosal artery (azPA) of the anterior cerebral artery (ACA). To measure the CBF we used a FAIR ASL MRI technique. $\boldsymbol{b}$, A reduced CBF was found in the cortex in 18-month-old apoE4 mice and in 12-and 18-month-old apoE-K0 mice compared with wild-type. A similar trend was observed in the thalamus, although it was not significant for the apoE-K0 mice. No significant differences were seen in the hippocampus.

The strongest potential confounding factor when performing $\mathrm{FC}$ analysis in animals, still remains the impact of anesthetics. Some studies in rats have used analgesic muscle relaxants, such as dexmedetomidine ( $\mathrm{Lu}$ et al., 2012) or medetomidine (Zhao et al., 2008), to limit the sedation level of the animals. However, maintaining a stable dose of these anesthetics for prolonged experiments $(\approx 2 \mathrm{~h})$ is barely reliable. More recently, it has been demonstrated that robust FC measures in rats and mice could be detected using a regime of low-dose isoflurane (Guilfoyle et al., 2013; Zhou et al., 2014). Compared with other anesthetic regimes, low-dose isoflurane seems to preserve resting-state networks in mice, with similar results to those obtained in awake animals (Jonckers et al., 2014). Isoflurane is also known to increase the resting blood flow, due to its moderate systemic vasodilator effect (Iida et al., 1998). In a separate experiment, we confirmed that both CBF and FC are dependent on isoflurane level, and they both rapidly decline with concentrations of anesthetic $>2.2 \%$, comparable to previous findings (Liu et al., 2011). We also measured an increased CBF and a reduced FC

by stimulating the maximum vessel vasodilation using a higher percentage of $\mathrm{N}_{2} \mathrm{O}$ in the gas composition (Drummond et al., 1987). However, the connectivity patterns, particularly between hippocampus and cortical structures, and the CBF were restored by switching the gas concentration to the standard experimental condition; together, these data indicate that the methodology used
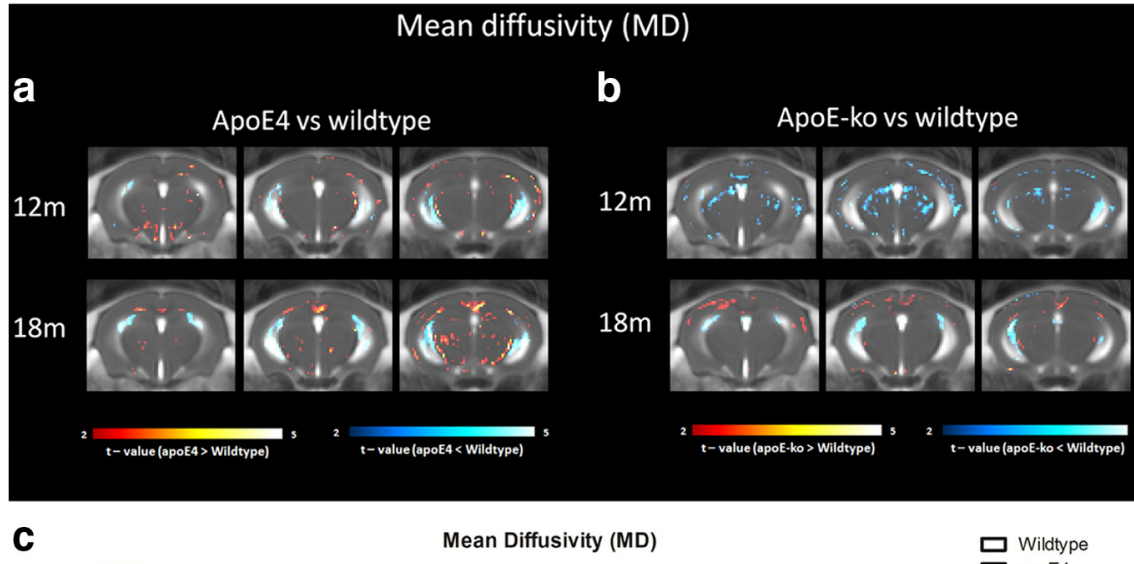

$\square$ Wildtype apoE4

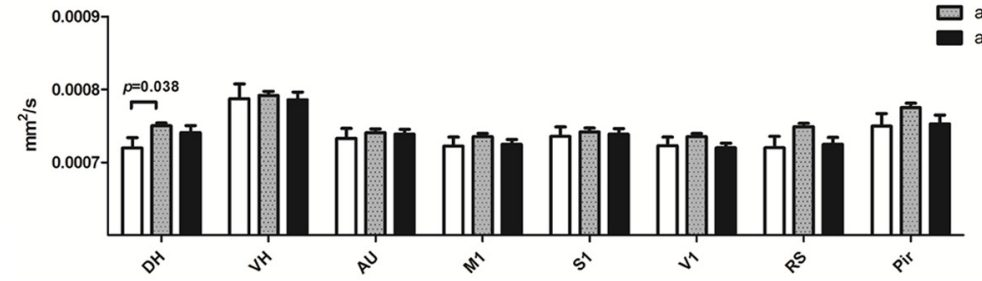

Figure 6. MD comparison between wild-type, apoE4, and apoE-KO mice. VBA indicate significant differences in MD at 12 and 18 months of age. Three rostral to caudal averaged MD maps are overlaid with voxels that showed a significant difference $(p<0.05$, minimum voxel cluster size $0.05 \mathrm{~mm}^{3}$ ). The voxel color indicates a negative or positive change in the apoE4 (a) or in the apoE-KO (b) mice compared with the wild-type mice of the same age. Few areas of significant differences are depicted in the explorative VBA; among them, an increase in MD in the DH of the apoE4 mice, independent of age, was also confirmed by ROI-based MANOVA (c). Increase in MD in the DH was also observed in the apoE-KO mice, although not significant ( $p>0.05$ ).

for this study is replicable and valid to measure functional connectivity, without reaching the condition of maximum vasodilation and without disrupting the neurovascular coupling. Furthermore, there are no reports on a possible effect of isoflurane on apoE-signaling, suggesting that this anesthetic does not interfere with the outcome of this study, as all animals were kept under the same conditions. 

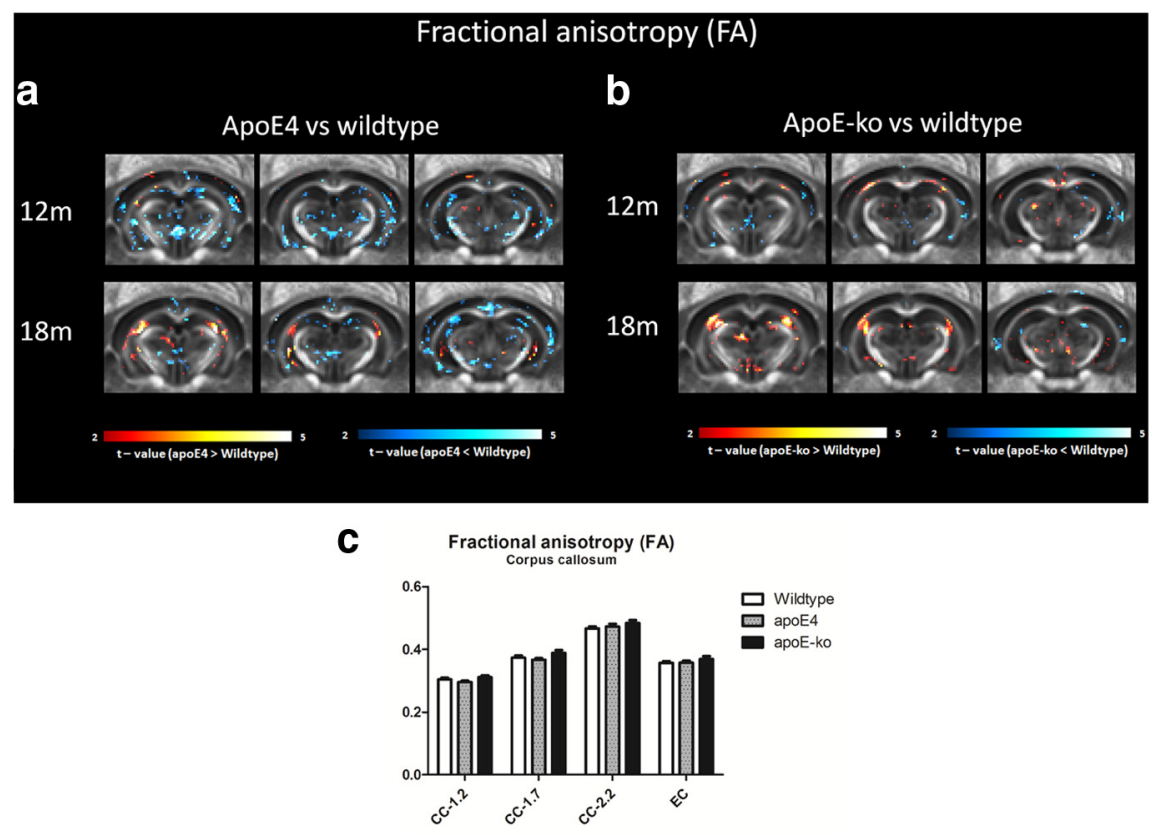

Figure 7. FA comparison between wild-type, apoE4 and apoE-KO mice. VBA indicate significant differences in $\mathrm{FA}$ at 12 and 18 months of age. Three rostral to caudal averaged FA maps are overlaid with voxels that showed a significant difference $(p<0.05$, minimum voxel cluster size $0.05 \mathrm{~mm}^{3}$ ). The voxel color indicates a negative or positive change in the apoE4 (a) or in the apoE-KO (b) mice compared with the wild-type mice of the same age. GM regions did not show FA differences between groups (data not shown), although a reduced $F A$ is visible in the molecular layer of the hippocampus in apoE4 mice, as depicted in the explorative VBA (a). ROI analyses of the CC in different bregma did not show statistical significant differences between FA due to genotype or aging (c).

FC in the aging mouse brain

Despite the limited literature about resting-state FC in rodents, our results exhibited many similarities with the resting-state networks described in mice by means of independent component analysis, in a similar anesthetic regime (Jonckers et al., 2011); in particular, we confirmed the presence of networks in several well defined cortical and subcortical areas of the mouse brain. It is however difficult to extrapolate whether these components are mainly unilateral or bilateral; most of the studies in rats clearly showed the presence of a bilateral cortical connectivity in several cortical regions (mainly visual, somatosensory, auditory, and motor) also under isoflurane (Liang et al., 2012; Zhou et al., 2014); nevertheless, not all studies in mice using isoflurane as anesthetic found the same degree of bilateral connectivity (Jonckers et al., 2011; Guilfoyle et al., 2013), whereas a more prominent interhemispheric connectivity has been found using other anesthetics (Nasrallah et al., 2014; Sforazzini et al., 2014). In this study, we detected significant interhemispheric direct connectivity (with partial correlation analysis) in hippocampal, motor, auditory, visual, and piriform cortices, and intrahemispheric connectivity between somatosensory, motor, and auditory cortices. Comparable resting-state connectivity in mice have been recently shown by high-resolution photoacoustic tomography, under a regime of ketamine + xylazine (Nasiriavanaki et al., 2014). Our ICA further confirmed these results, although revealing at the same time that the strongest interhemispheric components are found in the motor cortex and in the somatosensory-auditory-visual system.

As we expected, the connectivity found by ICA was largely dependent on the number of components selected before the analysis. In particular, when we reduced the number of components, the new components showed extended, and often inter- hemispheric, connectivity patterns but always keeping their meaningful anatomical location. This concept has been reported also in human studies, where a larger number of components from rsfMRI data probed a different hierarchy of functional networks. These newly revealed "subnetworks" were subsets of the larger networks found with lower number of components and they were interpreted as areas of slightly different function or as left versus right subnetworks (Smith et al., 2009).

An important finding in our study was a reduced FC in old animals compared with adulthood as measured with total correlation analysis. rsfMRI have been increasingly used as a tool to investigate the aging human brain in vivo. With few exceptions, most of the studies showed aging-related decrements in FC (Ferreira and Busatto, 2013). Because normal aging is associated with decline in cognition, the reduction in FC is thought to correlate with a disruption of neuronal connections and a deterioration of brain functioning in elderly people (Hedden and Gabrieli, 2004; Whalley et al., 2004). Compared with the total correlation results, partial correlation analyses revealed a more stable degree of connectivity at different ages.

\section{Resting-state $\mathrm{FC}$ and perfusion changes in the aging} mouse brain

In this study, we found a reduced total FC in apoE4 and apoE-KO mice, at both 12 and 18 months, compared with age-matched wild-type mice. In all animals, $\mathrm{CBF}$ was also measured, to test whether changes in vascular performance interfered with the FC results. Changes in cerebrovascular dynamics, such as impaired coupling between neural activity and hemodynamic response, might have directly influenced BOLD signal fluctuations and consequently FC changes (Liu, 2013).

\section{ApoE4}

Cross-sectional studies in young, middle-aged, and elderly human apoE- $\varepsilon 4$ carriers have reported reduced regional CBF and cerebral glucose metabolism over time, particularly in brain regions susceptible to pathological changes in $\mathrm{AD}$ (Scarmeas and Stern, 2006). In apoE- $\varepsilon 4$ subjects, a faster decline of regional CBF during aging has been shown compared with apoE- $\varepsilon 3$, suggesting its contribution to the increased risk of developing AD (Wierenga et al., 2013). In accordance, we demonstrated that apoE4 mice suffer from decreased cortical CBF at 18 months of age, whereas no differences were found at 12 months of age. Similar to the FC results, we showed a rapid decline of cerebral perfusion in these mice during aging, suggesting a strong aging effect. However, our data also highlight that changes in FC in apoE4 animals are measurable before CBF deficits. This finding suggests that the early FC decline in these mice is more likely attributable to the neural component on the BOLD signal, rather than to the possible interference of the vascular contribution. 

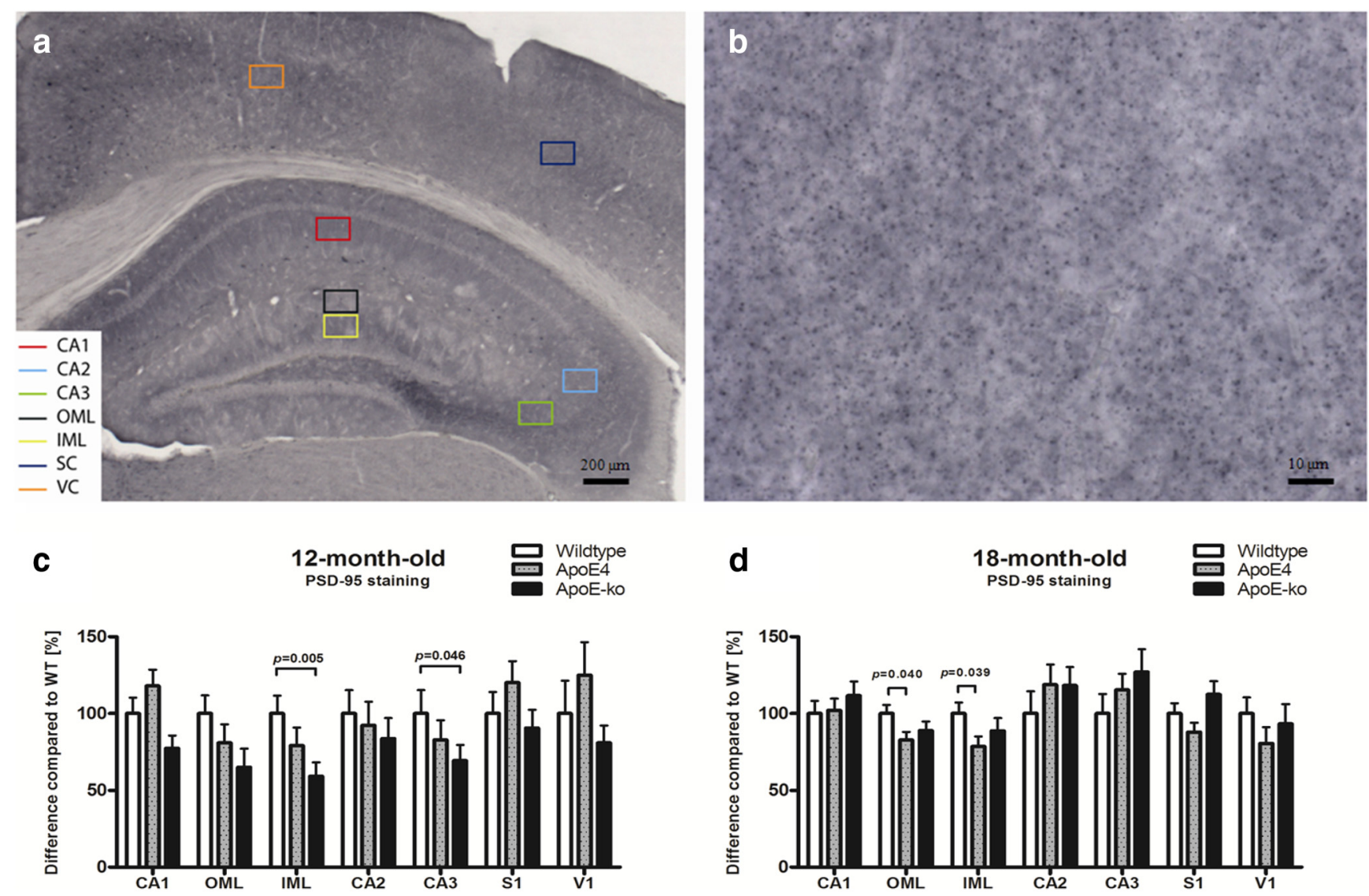

Figure 8. PSD-95 staining performed on brain sections of apoE- $\varepsilon 4$, apoE-K0, and wild-type mice. $\boldsymbol{a}, \boldsymbol{b}$, Representation of PSD-95-immunoreactive staining in hippocampal and cortical areas at two different magnifications ( $5 \times$ and $100 \times$, respectively). c, In 12-month-old animals we detected a significant decrease in PSD-95 levels in apoE-K0 mice compared with wild-type in the IML and CA3 of hippocampus. $\boldsymbol{d}$, In 18-month-old animals we show reduced PSD-95 levels in the apoE- $\varepsilon 4$ animals in the $0 \mathrm{ML}$ and in the IML, whereas no significant differences were seen between wild-type and apoE-KO mice. Values represent the mean and SEM.

\section{ApoE-KO}

In apoE-KO mice we found a concomitant reduction in $\mathrm{CBF}$ and resting-state connectivity at both ages. These mice are commonly used as models for vascular pathologies, as they develop aortic aneurysms, atherosclerotic plaques, and endothelial dysfunction throughout their life (Crauwels et al., 2003; Trollope et al., 2011). No investigations on resting-state fMRI were previously performed in apoE-KO mice; however, it is known that, together with vascular deficits, these mice also develop compromised synaptic plasticity (Masliah et al., 1995; Blain et al., 2006) and cognitive performance (Gordon et al., 1995; Masliah et al., 1995; Oitzl et al., 1997; Krzywkowski et al., 1999). Our results suggest that the FC decline observed in these animals reflects the contribution of both impaired neurovascular coupling and damaged neural activity; we hypothesize that the severe vascular pathology, which develop spontaneously in these mice at early age, could have accelerated the occurrence of brain injury by overexposure to stress factors, like cerebral hypoperfusion; the absence of apoE could have further aggravated the synaptic repair processes, leading to loss of neuronal connectivity. Supportively, we found a positive correlation between $\mathrm{CBF}$ and postsynaptic density (in sampled regions). Although the correlation of these two measures do not imply a cause-effect mechanism, it does support an association between neuronal and vascular health. It is also interesting to note that the changes in adult apoE-KO mice mirror the observations in the old apoE4 mice; this underlines a certain degree of similarity between these models, although demonstrating a more severe pathology in the $\mathrm{KO}$ mice.

\section{Structural changes and postsynaptic density in the aging mouse brain}

DT-MRI studies in apoE4 and apoE-KO mice are lacking, but changes in diffusion parameters have been reported in human studies; FA reductions in WM of APOE- $\varepsilon 4$ carriers have been shown (Nierenberg et al., 2005; Honea et al., 2009; Heise et al., 2011); two studies also reported diffusion differences in hippocampal structures (Nierenberg et al., 2005; Persson et al., 2006). Nevertheless, these dissimilarities were consistent across different ages, suggesting that APOE affects WM and GM microstructure proprieties from early adulthood, without directly reflecting the associated risk of developing $\mathrm{AD}$ (Westlye et al., 2012).

With our exploratory voxel-based analyses, we detected similar changes in WM and GM microstructure in apoE4 mice. However, the only significant results confirmed by MANOVA were an age-independent increased MD in the CC, EC, and DH of the apoE4 mice. It is interesting to note that the changes in MD in WM were reflected by increased parallel and radial diffusivity, but without changes in tensor shape; this could indicate a different structural density of the fibers, resulting in more space for the water molecules to move. Brain atrophy and WM loss could have also increased the partial volume effect in these relatively thin areas, explaining these results. The association between an increased MD (and RD) in the CC and myelin degradation of the axonal bundles has been proposed by previous studies (Song et al., 2005). To verify this hypothesis and directly measure brain atrophy in vivo, voxel-based morphometry (Ellegood et al., 
2012) or electron microscopy methods could be applied in future studies.

Higher hippocampal MD has been consistently associated with neurodegenerative processes in both $\mathrm{AD}$ patients and animal models for AD (Zerbi et al., 2013; Zhang et al., 2014). These structural modifications in apoE4 mice are likely not related to neurodegeneration, as neural loss is not expected in this model at a young age. It is possible instead that increased inflammation processes could have driven structural alterations and hippocampal atrophy (Yin et al., 2011).

Furthermore, we did not find differences between apoE-KO and wild-type mice in DT-MRI parameters, suggesting that for these models, water diffusion changes are mild even in presence of severe functional deficits. The structural changes found in these mice were also not related to vascular or synaptic deficits, suggesting a link to the role of apoE in synaptic development, dendrite formation, and axonal guidance.

Synaptic loss and disconnection are strongly related with cognitive decline in AD and may influence FC (Selkoe, 2002; Serrano-Pozo et al., 2011). We therefore determined the postsynaptic density in our mouse models to characterize neural deficits in relation with FC. Compared with wild-type, we found reduced PSD-95 levels in 12-month-old apoE-KO mice, and also in the 18-month-old apoE4 mice. Interestingly, the present results mirror the hypoperfusion deficits observed in these animals, confirming the relation between apoE, neuronal and vascular health. Furthermore, these data suggest impaired synaptic maintenance by the apoE4 isoform, which is even more pronounced by its absence. This can be linked to the lower efficacy of the apoE- $\varepsilon 4$ isoform as cholesterol transporter, resulting in reduced contribution to synaptogenesis and maintenance of synaptic connections (Poirier et al., 1995; Mauch et al., 2001; Pfrieger, 2003).

In conclusion, with this study we provide evidence for a relation between apoE genotype, vascular risk factors and functional connectivity. Despite the technical challenges, we demonstrate that rsfMRI, combined with other MR neuroimaging techniques, can be used as powerful tool to investigate early neuropathology and aging effects in translational research.

\section{Notes}

Supplemental material for this article is available at https://www.radboudumc. $\mathrm{nl} /$ Zorg/Afdelingen/anatomie/SectieAnatomie/Documents/20140818\% 20Supplementary\%20material\%20Valerio\%20Zerbi.pdf. This material has not been peer reviewed.

\section{References}

Biswal B, Yetkin FZ, Haughton VM, Hyde JS (1995) Functional connectivity in the motor cortex of resting human brain using echo-planar MRI. Magn Reson Med 34:537-541. CrossRef Medline

Blain JF, Sullivan PM, Poirier J (2006) A deficit in astroglial organization causes the impaired reactive sprouting in human apolipoprotein E4 targeted replacement mice. Neurobiol Dis 21:505-514. CrossRef Medline

Bondi MW, Houston WS, Eyler LT, Brown GG (2005) fMRI evidence of compensatory mechanisms in older adults at genetic risk for Alzheimer disease. Neurology 64:501-508. CrossRef Medline

Bookheimer SY, Strojwas MH, Cohen MS, Saunders AM, Pericak-Vance MA, Mazziotta JC, Small GW (2000) Patterns of brain activation in people at risk for Alzheimer's disease. N Engl J Med 343:450-456. CrossRef Medline

Brown JA, Terashima KH, Burggren AC, Ercoli LM, Miller KJ, Small GW, Bookheimer SY (2011) Brain network local interconnectivity loss in aging APOE-4 allele carriers. Proc Natl Acad Sci U S A 108:20760-20765. CrossRef Medline

Bu G (2009) Apolipoprotein E and its receptors in Alzheimer's disease: pathways, pathogenesis and therapy. Nat Rev Neurosci 10:333-344. CrossRef Medline

Crauwels HM, Van Hove CE, Holvoet P, Herman AG, Bult H (2003) Plaque-associated endothelial dysfunction in apolipoprotein E-deficient mice on a regular diet: effect of human apolipoprotein AI. Cardiovasc Res 59:189-199. CrossRef Medline

Damoiseaux JS, Rombouts SA, Barkhof F, Scheltens P, Stam CJ, Smith SM, Beckmann CF (2006) Consistent resting-state networks across healthy subjects. Proc Natl Acad Sci U S A 103:13848-13853. CrossRef Medline

De Luca M, Beckmann CF, De Stefano N, Matthews PM, Smith SM (2006) fMRI resting state networks define distinct modes of long-distance interactions in the human brain. Neuroimage 29:1359-1367. CrossRef Medline

Drummond JC, Scheller MS, Todd MM (1987) The effect of nitrous oxide on cortical cerebral blood flow during anesthesia with halothane and isoflurane, with and without morphine, in the rabbit. Anesth Analg 66: 1083-1089. Medline

Dubois A, Hérard AS, Flandin G, Duchesnay E, Besret L, Frouin V, Hantraye P, Bonvento G, Delzescaux T (2008) Quantitative validation of voxelwise statistical analyses of autoradiographic rat brain volumes: application to unilateral visual stimulation. Neuroimage 40:482-494. CrossRef Medline

Ellegood J, Henkelman RM, Lerch JP (2012) Neuroanatomical assessment of the integrin [beta3] mouse model related to autism and the serotonin system using high resolution MRI. Front Psychiatry 3:37. CrossRef Medline

Ferreira LK, Busatto GF (2013) Resting-state functional connectivity in normal brain aging. Neurosci Biobehav Rev 37:384-400. CrossRef Medline

Filippini N, MacIntosh BJ, Hough MG, Goodwin GM, Frisoni GB, Smith SM, Matthews PM, Beckmann CF, Mackay CE (2009) Distinct patterns of brain activity in young carriers of the APOE-epsilon4 allele. Proc Natl Acad Sci U S A 106:7209-7214. CrossRef Medline

Fleisher AS, Sherzai A, Taylor C, Langbaum JB, Chen K, Buxton RB (2009) Resting-state BOLD networks versus task-associated functional MRI for distinguishing Alzheimer's disease risk groups. Neuroimage 47:16781690. CrossRef Medline

Gordon I, Grauer E, Genis I, Sehayek E, Michaelson DM (1995) Memory deficits and cholinergic impairments in apolipoprotein E-deficient mice. Neurosci Lett 199:1-4. CrossRef Medline

Greicius M (2008) Resting-state functional connectivity in neuropsychiatric disorders. Curr Opin Neurol 21:424-430. CrossRef Medline

Greicius MD, Srivastava G, Reiss AL, Menon V (2004) Default-mode network activity distinguishes Alzheimer's disease from healthy aging: evidence from functional MRI. Proc Natl Acad Sci U S A 101:4637-4642. CrossRef Medline

Guilfoyle DN, Gerum SV, Sanchez JL, Balla A, Sershen H, Javitt DC, Hoptman MJ (2013) Functional connectivity fMRI in mouse brain at 7T using isoflurane. J Neurosci Methods 214:144-148. CrossRef Medline

Harsan LA, Paul D, Schnell S, Kreher BW, Hennig J, Staiger JF, von Elverfeldt D (2010) In vivo diffusion tensor magnetic resonance imaging and fiber tracking of the mouse brain. NMR Biomed 23:884-896. CrossRef Medline

Hedden T, Gabrieli JD (2004) Insights into the ageing mind: a view from cognitive neuroscience. Nat Rev Neurosci 5:87-96. CrossRef Medline

Heise V, Filippini N, Ebmeier KP, Mackay CE (2011) The APOE varepsilon4 allele modulates brain white matter integrity in healthy adults. Mol Psychiatry 16:908-916. CrossRef Medline

Herscovitch P, Raichle ME (1985) What is the correct value for the brainblood partition coefficient for water? J Cereb Blood Flow Metab 5:65-69. CrossRef Medline

Honea RA, Vidoni E, Harsha A, Burns JM (2009) Impact of APOE on the healthy aging brain: a voxel-based MRI and DTI study. J Alzheimers Dis 18:553-564. CrossRef Medline

Iida $\mathrm{H}$, Ohata H, Iida M, Watanabe Y, Dohi S (1998) Isoflurane and sevoflurane induce vasodilation of cerebral vessels via ATP-sensitive $\mathrm{K}+$ channel activation. Anesthesiology 89:954-960. CrossRef Medline

Jansen D, Zerbi V, Janssen CI, Dederen PJ, Mutsaers MP, Hafkemeijer A, Janssen AL, Nobelen CL, Veltien A, Asten JJ, Heerschap A, Kiliaan AJ (2013) A longitudinal study of cognition, proton MR spectroscopy and 
synaptic and neuronal pathology in aging wild-type and A $\beta$ PPswePS1dE9 mice. PLoS One 8:e63643. CrossRef Medline

Jenkinson M, Beckmann CF, Behrens TE, Woolrich MW, Smith SM (2012) FSL. Neuroimage 62:782-790. CrossRef Medline

Jonckers E, Van Audekerke J, De Visscher G, Van der Linden A, Verhoye M (2011) Functional connectivity fMRI of the rodent brain: comparison of functional connectivity networks in rat and mouse. PLoS One 6:e18876. CrossRef Medline

Jonckers E, Delgado YPR, Shah D, Guglielmetti C, Verhoye M, Van der Linden A (2014) Different anesthesia regimes modulate the functional connectivity outcome in mice. Magn Reson Med 72:1103-1112. CrossRef Medline

Kalthoff D, Seehafer JU, Po C, Wiedermann D, Hoehn M (2011) Functional connectivity in the rat at $11.7 \mathrm{~T}$ : impact of physiological noise in resting state fMRI. Neuroimage 54:2828-2839. CrossRef Medline

Kim SG (1995) Quantification of relative cerebral blood flow change by flow-sensitive alternating inversion recovery (FAIR) technique: application to functional mapping. Magn Reson Med 34:293-301. CrossRef Medline

Krzywkowski P, Ghribi O, Gagné J, Chabot C, Kar S, Rochford J, Massicotte G, Poirier J (1999) Cholinergic systems and long-term potentiation in memory-impaired apolipoprotein E-deficient mice. Neuroscience 92: 1273-1286. CrossRef Medline

Leithner C, Müller S, Füchtemeier M, Lindauer U, Dirnagl U, Royl G (2010) Determination of the brain-blood partition coefficient for water in mice using MRI. J Cereb Blood Flow Metab 30:1821-1824. CrossRef Medline

Liang Z, King J, Zhang N (2012) Intrinsic organization of the anesthetized brain. J Neurosci 32:10183-10191. CrossRef Medline

Lin AL, Qin Q, Zhao X, Duong TQ (2012) Blood longitudinal (T 1) and transverse (T 2) relaxation time constants at 11.7 Tesla. MAGMA 25:245249. CrossRef Medline

Liu CC, Kanekiyo T, Xu H, Bu G (2013) Apolipoprotein E and Alzheimer disease: risk, mechanisms and therapy. Nat Rev Neurol 9:106-118. CrossRef Medline

Liu TT (2013) Neurovascular factors in resting-state functional MRI. Neuroimage 80:339-348. CrossRef Medline

Liu X, Zhu XH, Zhang Y, Chen W (2011) Neural origin of spontaneous hemodynamic fluctuations in rats under burst-suppression anesthesia condition. Cereb Cortex 21:374-384. CrossRef Medline

Lu H, Zou Q, Gu H, Raichle ME, Stein EA, Yang Y (2012) Rat brains also have a default mode network. Proc Natl Acad Sci U S A 109:3979-3984. CrossRef Medline

Machulda MM, Jones DT, Vemuri P, McDade E, Avula R, Przybelski S, Boeve BF, Knopman DS, Petersen RC, Jack CR Jr (2011) Effect of APOE epsilon4 status on intrinsic network connectivity in cognitively normal elderly subjects. Arch Neurol 68:1131-1136. CrossRef Medline

Mahley RW, Rall SC Jr (2000) Apolipoprotein E: far more than a lipid transport protein. Annu Rev Genomics Hum Genet 1:507-537. CrossRef Medline

Mahley RW, Weisgraber KH, Huang Y (2006) Apolipoprotein E4: a causative factor and therapeutic target in neuropathology, including Alzheimer's disease. Proc Natl Acad Sci U S A 103:5644-5651. CrossRef Medline

Masliah E, Mallory M, Ge N, Alford M, Veinbergs I, Roses AD (1995a) Neurodegeneration in the central nervous system of apoE-deficient mice. Exp Neurol 136:107-122. CrossRef Medline

Mauch DH, Nägler K, Schumacher S, Göritz C, Müller EC, Otto A, Pfrieger FW (2001) CNS synaptogenesis promoted by glia-derived cholesterol. Science 294:1354-1357. CrossRef Medline

Nasiriavanaki M, Xia J, Wan H, Bauer AQ, Culver JP, Wang LV (2014) High-resolution photoacoustic tomography of resting-state functional connectivity in the mouse brain. Proc Natl Acad Sci U S A 111:21-26. CrossRef Medline

Nasrallah FA, Tay HC, Chuang KH (2014) Detection of functional connectivity in the resting mouse brain. Neuroimage 86:417-424. CrossRef Medline

Nierenberg J, Pomara N, Hoptman MJ, Sidtis JJ, Ardekani BA, Lim KO (2005) Abnormal white matter integrity in healthy apolipoprotein E epsilon4 carriers. Neuroreport 16:1369-1372. CrossRef Medline

O’Brien JL, O’Keefe KM, LaViolette PS, DeLuca AN, Blacker D, Dickerson BC, Sperling RA (2010) Longitudinal fMRI in elderly reveals loss of hip- pocampal activation with clinical decline. Neurology 74:1969-1976. CrossRef Medline

Oitzl MS, Mulder M, Lucassen PJ, Havekes LM, Grootendorst J, de Kloet ER (1997) Severe learning deficits in apolipoprotein E-knock-out mice in a water maze task. Brain Res 752:189-196. CrossRef Medline

Paxinos G, Franklin KBJ (2004) The mouse brain in stereotaxic coordinates, Ed 2. Amsterdam; Boston: Elsevier Academic.

Persson J, Lind J, Larsson A, Ingvar M, Cruts M, Van Broeckhoven C, Adolfsson R, Nilsson LG, Nyberg L (2006) Altered brain white matter integrity in healthy carriers of the APOE epsilon4 allele: a risk for $\mathrm{AD}$ ? Neurology 66:1029-1033. CrossRef Medline

Pfrieger FW (2003) Cholesterol homeostasis and function in neurons of the central nervous system. Cell Mol Life Sci 60:1158-1171. Medline

Piedrahita JA, Zhang SH, Hagaman JR, Oliver PM, Maeda N (1992) Generation of mice carrying a mutant apolipoprotein $\mathrm{E}$ gene inactivated by gene targeting in embryonic stem cells. Proc Natl Acad Sci U S A 89:44714475. CrossRef Medline

Poirier J, Minnich A, Davignon J (1995) Apolipoprotein E, synaptic plasticity and Alzheimer's disease. Ann Med 27:663-670. CrossRef Medline

Sawiak SJ, Wood NI, Williams GB, Morton AJ, Carpenter TA (2009) Voxelbased morphometry in the R6/2 transgenic mouse reveals differences between genotypes not seen with manual 2D morphometry. Neurobiol Dis 33:20-27. CrossRef Medline

Scarmeas N, Stern Y (2006) Imaging studies and APOE genotype in persons at risk for Alzheimer's disease. Curr Psychiatry Rep 8:11-17. CrossRef Medline

Selkoe DJ (2002) Alzheimer's disease is a synaptic failure. Science 298:789791. CrossRef Medline

Serrano-Pozo A, Frosch MP, Masliah E, Hyman BT (2011) Neuropathological alterations in Alzheimer disease. Cold Spring Harb Perspect Med 1:a006189. CrossRef Medline

Sforazzini F, Schwarz AJ, Galbusera A, Bifone A, Gozzi A (2014) Distributed BOLD and CBV-weighted resting-state networks in the mouse brain. Neuroimage 87:403-415. CrossRef Medline

Sheline YI, Morris JC, Snyder AZ, Price JL, Yan Z, D'Angelo G, Liu C, Dixit S, Benzinger T, Fagan A, Goate A, Mintun MA (2010) APOE4 allele disrupts resting state fMRI connectivity in the absence of amyloid plaques or decreased CSF A $\beta 42$. J Neurosci 30:17035-17040. CrossRef Medline

Smith SM, Fox PT, Miller KL, Glahn DC, Fox PM, Mackay CE, Filippini N, Watkins KE, Toro R, Laird AR, Beckmann CF (2009) Correspondence of the brain's functional architecture during activation and rest. Proc Natl Acad Sci U S A 106:13040-13045. CrossRef Medline

Song SK, Yoshino J, Le TQ, Lin SJ, Sun SW, Cross AH, Armstrong RC (2005) Demyelination increases radial diffusivity in corpus callosum of mouse brain. Neuroimage 26:132-140. CrossRef Medline

Song XW, Dong ZY, Long XY, Li SF, Zuo XN, Zhu CZ, He Y, Yan CG, Zang YF (2011) REST: a toolkit for resting-state functional magnetic resonance imaging data processing. PLoS One 6:e25031. CrossRef Medline

Sullivan PM, Mezdour H, Aratani Y, Knouff C, Najib J, Reddick RL, Quarfordt SH, Maeda N (1997) Targeted replacement of the mouse apolipoprotein $\mathrm{E}$ gene with the common human APOE3 allele enhances diet-induced hypercholesterolemia and atherosclerosis. J Biol Chem 272:17972-17980. CrossRef Medline

Trachtenberg AJ, Filippini N, Mackay CE (2012) The effects of APOEepsilon4 on the BOLD response. Neurobiol Aging 33:323-334. CrossRef Medline

Trollope A, Moxon JV, Moran CS, Golledge J (2011) Animal models of abdominal aortic aneurysm and their role in furthering management of human disease. Cardiovasc Pathol 20:114-123. CrossRef Medline

Ullmann JF, Watson C, Janke AL, Kurniawan ND, Reutens DC (2013) A segmentation protocol and MRI atlas of the C57BL/6J mouse neocortex. Neuroimage 78:196-203. CrossRef Medline

Verghese PB, Castellano JM, Holtzman DM (2011) Apolipoprotein E in Alzheimer's disease and other neurological disorders. Lancet Neurol 10: 241-252. CrossRef Medline

Westlye LT, Reinvang I, Rootwelt H, Espeseth T (2012) Effects of APOE on brain white matter microstructure in healthy adults. Neurology 79:19611969. CrossRef Medline

Whalley LJ, Deary IJ, Appleton CL, Starr JM (2004) Cognitive reserve and the neurobiology of cognitive aging. Ageing Res Rev 3:369-382. CrossRef Medline 
Wierenga CE, Clark LR, Dev SI, Shin DD, Jurick SM, Rissman RA, Liu TT, Bondi MW (2013) Interaction of age and APOE genotype on cerebral blood flow at rest. J Alzheimers Dis 34:921-935. CrossRef Medline

Yin JX, Turner GH, Lin HJ, Coons SW, Shi J (2011) Deficits in spatial learning and memory is associated with hippocampal volume loss in aged apolipoprotein E4 mice. J Alzheimers Dis 27:89-98. CrossRef Medline

Zerbi V, Kleinnijenhuis M, Fang X, Jansen D, Veltien A, Van Asten J, Timmer N, Dederen PJ, Kiliaan AJ, Heerschap A (2013) Gray and white matter degeneration revealed by diffusion in an Alzheimer mouse model. Neurobiol Aging 34:1440-1450. CrossRef Medline

Zerbi V, Jansen D, Wiesmann M, Fang X, Broersen LM, Veltien A, Heerschap A, Kiliaan AJ (2014) Multinutrient diets improve cerebral perfusion and neuroprotection in a murine model of Alzheimer's disease. Neurobiol Aging 35:600-613. CrossRef Medline

Zhang B, Xu Y, Zhu B, Kantarci K (2014) The role of diffusion tensor imag- ing in detecting microstructural changes in prodromal Alzheimer's disease. CNS Neurosci Ther 20:3-9. CrossRef Medline

Zhao F, Zhao T, Zhou L, Wu Q, Hu X (2008) BOLD study of stimulationinduced neural activity and resting-state connectivity in medetomidinesedated rat. Neuroimage 39:248-260. CrossRef Medline

Zhou IY, Liang YX, Chan RW, Gao PP, Cheng JS, Hu Y, So KF, Wu EX (2014) Brain resting-state functional MRI connectivity: morphological foundation and plasticity. Neuroimage 84:1-10. CrossRef Medline

Zlokovic BV (2011) Neurovascular pathways to neurodegeneration in Alzheimer's disease and other disorders. Nat Rev Neurosci 12:723-738. CrossRef Medline

Zlokovic BV (2013) Cerebrovascular effects of apolipoprotein E: implications for Alzheimer disease. JAMA Neurol 70:440-444. CrossRef Medline

Zwiers MP (2010) Patching cardiac and head motion artefacts in diffusionweighted images. Neuroimage 53:565-575. CrossRef Medline 